\title{
TAPERED BUBBLE COLUMN USING PSEUDOPLASTIC NON-NEWTONIAN LIQUIDS - EMPIRICAL CORRELATION FOR PRESSURE DROP
}

\author{
Sumit Kumar Jana1, *, Sudip Kumar Das²
}

https:

\begin{abstract}
Experimental studies on the frictional pressure drop in two tapered bubble columns using non-Newtonian pseudoplastic liquid have been reported. The effects of taper angle on frictional pressure drop have been investigated. Empirical correlation has been developed for the prediction of the frictional pressure drop as a function of various measurable parameters of the system. The correlation is statistically acceptable.
\end{abstract}

Keywords: bubble column, non-Newtonian liquid, pressure drop.

\section{Introduction}

Bubble columns are extensively used as absorbers, strippers, reactors, fermenters, etc. in chemical process industries. The main advantages of bubble column are the following: it has no moving parts, simple construction, good mixing, heat and mass transfer capacity, temperature control, minimum maintenance, and low capital cost. It also has some disadvantages, like bubbles coalescence, high-pressure drop, considerable back-mixing in both phases, short residence time of gas, and complex hydrodynamics flow patterns. Biotechnology, food processing and pharmaceutical processes frequently used bubble column and often used to process highly viscous liquid. In general the hydrodynamic parameters in a bubble column depend on the operating conditions, column geometry, properties of gas and liquid, and the gas distribution system [1]. Detail literature review was reported in $[2,3]$. However, only few literature sources are available on bubble column using pseudoplastic nonNewtonian liquids. Pradhan et al. [4] studied gas holdup characteristics in a bubble column containing either helical coils or straight tube internals using nonNewtonian liquids. Mandal et al. [5, 6] studied the

\footnotetext{
${ }^{1}$ Birla Institute of Technology, Mesra-835215, Ranchi, India

${ }^{2}$ University of Calcutta, 92, A. P. C. Road, Kolkata - 700 009, India

sumitkrjana@bitmesra.ac.in

(C) Jana S., Das S., 2017
}

hydrodynamic characteristics in downflow bubble column using both Newtonian and non-Newtonian liquids and developed empirical correlation for holdup and pressure drop prediction. Frank et al. [7] presented flow of bubble train in non-Newtonian fluids. Zhan et al. [8] reported the hydrodynamic behaviour of tapered slurry bubble column with the angle $1.91^{\circ}$ and height $3 \mathrm{~m}$. The effects of operating parameters on the flow regime, gas holdup and pressure drop were investigated. Chandarkar et al. [9] studied the gas dispersion behaviour in non-Newtonian liquid in vertical upflow bubble column. Gomez-Diaz et al. [10] studied carbon dioxide absorption in bubble column using non-Newtonian liquids. Anastasiou et al. [11] reported empirical correlation for gas holdup prediction for finely dispersed gas through nonNewtonian liquid in a bubble column. Amirnia et al. [12] reported the bubble rise in the non-Newtonian liquids and observed the changes of shape during the flow and concluded that small bubbles flow vertically whereas big bubbles follow zig-zag path. Passos et al. [13] studied the hydrodynamics of surfactant addition in a bubble column using non-Newtonian liquids. Fernandez et al. [14] demonstrated the difference in system hydrodynamics in the bubble column using Newtonian and non-Newtonian liquid in terms of bubble buoyancy, bubble shape, turbulence level, and drainage of liquid film between bubbles. Sayeed-Bin-Asad [15] reviewed the bubble flow in non-Newtonian liquids and concluded that the knowledge of bubble hydrodynamics is necessary for the prediction of transport coefficients and also to optimise the process variables for design and to achieve maximum productivity in industrial scale. Hence the bubble rise through non-Newtonian liquid are very complex and poorly understood phenomena but its knowledge is very important for proper design of the bubble column [1, 12, 15]. In our earlier publications we have clearly demonstrated the advantages of taper bubble column over the conventional cylindrical column $[2,16]$. In the present study, experimental two-phase pressure drop on taper bubble columns using non-Newtonian liquids has been analysed and empirical correlation has been developed to predict the frictional pressure drop. 


\section{Experimental}

Fig. 1 shows the schematic diagram of the experimental setup [2] and Fig. 2 - the photo. It consists of tapered bubble column, manometers for pressure measurement, distributor (D) to distribute the air, compressor (C), pressure gauge (PG), rotameter (RG) for flow measures, and other accessories. The tapered bubble columns are made of thick perspex and are square shaped. Perforated plates $(0.0127 \mathrm{~m}$ thick) made

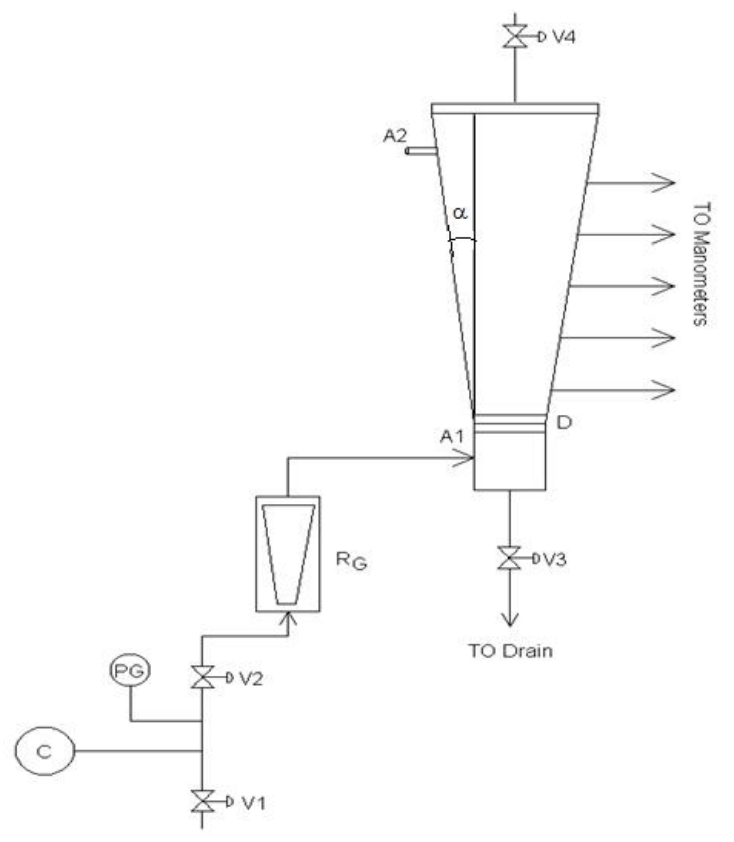

Fig. 1. Schematic diagram of experimental setup [2]: A1 - air inlet; A2 - air outlet; D - distributor; C - compressor; $\mathrm{PG}$ - pressure gauge; $\mathrm{R}_{\mathrm{G}}$ - gas rotameter; $\mathrm{V} 1-\mathrm{V} 4$ - control valves of perspex of different hole diameter were used for air distribution and connected with the column by means of flanges. Air inlet is provided at the bottom by means of two opposite nozzles of $4 \mathrm{~mm}$ diameter. The air is distributed through the perforated plate and enters the column. Columns were fitted vertically by means of clamps to avoid any vibration. Two tapered bubble column of different cross-section areas are used for the experiment. Detailed dimensions of the columns are shown in Table 1.

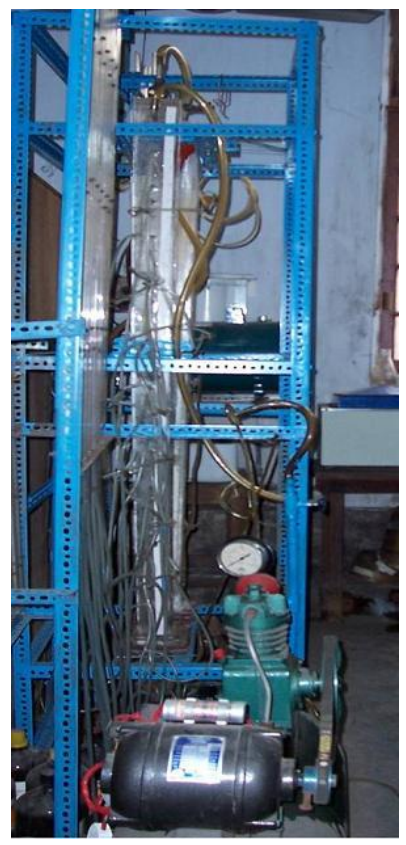

Fig. 2. Experimental setup (photo)

Dimensions of the bubble columns

\begin{tabular}{|l|c|c|}
\hline \multicolumn{1}{|c|}{ Characteristic parameters } & Larger tapered bubble column, TB2 & Smaller tapered bubble column, TB1 \\
\hline Thickness of perspex sheet, $\mathrm{m}$ & 0.0127 & 0.0127 \\
\hline Height of column, $\mathrm{m}$ & 1.83 & $0.0762 \times 0.0762$ \\
\hline Top plate area, $\mathrm{m}^{2}$ & $0.1016 \times 0.1016$ & $0.0508 \times 0.0508$ \\
\hline Bottom plate area, $\mathrm{m}^{2}$ & $0.0508 \times 0.0508$ & $0.0605 \leq D_{c} \leq 0.0614$ \\
\hline Equivalent diameter, $\mathrm{m}$ & $0.0692 \leq D_{c} \leq 0.0710$ & 0.44 \\
\hline Taper angle( $\alpha$ ), deg. & 0.86 & $0.00277,0.00357,0.00436$ \\
\hline Hole diameter of different sieve plates used, $\mathrm{m}$ & $0.00277,0.00357,0.00436$ & 50 \\
\hline Hole number of sieve plate & 50 & square \\
\hline Pitch & square & 0.0508 \\
\hline Distance from the air distributor for & 0.0508 & 0.2032 \\
\hline Taping no. $1, \mathrm{~m}$ & & 0.3556 \\
\hline Taping no., $\mathrm{m}$ & 0.2032 & 0.5080 \\
\hline Taping no.3, $\mathrm{m}$ & 0.3556 & 0.6604 \\
\hline Taping no.4, $\mathrm{m}$ & 0.5080 & 0.8128 \\
\hline Taping no.5, $\mathrm{m}$ & 0.6604 & \\
\hline Taping no.6, $\mathrm{m}$ & 0.8128 & \\
\hline
\end{tabular}


Physical properties of the SCMC solutions

\begin{tabular}{|c|c|c|c|c|}
\hline Concentration, $\mathrm{kg} / \mathrm{m}^{3}$ & Flow behavior index $n$ & Consistency index $K, \mathrm{Ns}^{\mathrm{n}} / \mathrm{m}^{2}$ & Density $\rho, \mathrm{kg} / \mathrm{m}^{3}$ & Surface tension $\sigma, \mathrm{N} / \mathrm{m}$ \\
\hline 0.2 & 0.9013 & 0.0138 & 1001.69 & 0.07834 \\
0.4 & 0.7443 & 0.1149 & 1002.13 & 0.08003 \\
0.6 & 0.6605 & 0.3154 & 1002.87 & 0.08142 \\
0.8 & 0.6015 & 0.6486 & 1003.83 & 0.08320 \\
\hline
\end{tabular}

Four different sodium salt of carboxymethyl cellulose $(\mathrm{SCMC})$ with concentrations of $0.2-0.8 \mathrm{~kg} / \mathrm{m}^{3}$ were used for the experiment. The dilute solution of SCMC is a time independent pseudoplastic fluid and its rheology is described by Oswald de-Waele or Power law model:

$$
\tau=K\left(-\frac{d V}{d r}\right)^{n}
$$

where $K$ and $n$ are the constants for the particular liquid with $n<1$. The constant $K$ is known as consistency index of the liquid and the higher the value of $K$ the more viscous the fluid is. The rheological properties of the SCMC solutions were measured by means of pipeline viscometer. DuNouy tensiometer and specific gravity bottle were used to measure surface tension and density, respectively. The physical properties of the liquid are shown in Table 2.

The liquid heights used for the experiments were $1.12,1.17$ and $1.22 \mathrm{~m}$ for both columns. The air at the pressure of $1 \mathrm{~kg} / \mathrm{cm}^{2}$ gauge was introduced into the columns, and under steady state condition, readings of manometers attached to the tapings were noted and also the height of liquid column was noted. From the manometer readings pressure drop was determined. The liquid holdup for a particular gas flow rate is the fraction of the total gas-liquid volume that is occupied by the liquid and determined experimentally. The experiments were repeated for a number of times to ensure the reproducibility of the data. The temperature was maintained at $303 \pm 2 \mathrm{~K}$.

\section{Results and Discussion}

\subsection{Frictional Pressure Drop Determination}

The pressure drop in the vertical flow is the sum of the frictional pressure $\left(\Delta P_{f}\right)$, the hydrostatic head component $\left(\Delta P_{h}\right)$ and pressure drop due to accelerative effects $\left(\Delta P_{a}\right)$. Thus,

$$
\Delta P_{T}=\Delta P_{f}+\Delta P_{h}+\Delta P_{a}
$$

According to Hughmark and Pressburg [17] and Friedel [18] acceleration component $\left(\Delta P_{a}\right)$ is insignificant compared to the total pressure drop. Hence,

$$
\Delta P_{T}=\Delta P_{f}+\Delta P_{h}
$$

Many researchers, e.g. Ros [19], Hagedron and Brown [20], have considered the in-situ density of the two-phase system for the calculation of the hydrostatic head by assuming the overall gas holdup in the column is the same everywhere:

$$
\Delta P_{h}=g \Delta Z\left(\rho_{l} \varepsilon_{l}+\rho_{g} \varepsilon_{g}\right)
$$

As $\rho_{l} \gg \rho_{g}$ the second term within the bracket of the right hand side can be neglected. Thus substituting $\Delta P_{h}$ from Eq. (4) in Eq. (3), one gets:

$$
\Delta P_{T}=\Delta P_{f}+g \Delta Z \rho_{l} \varepsilon_{l}
$$

Therefore,

$$
\Delta P_{f}=\Delta P_{T}-g \Delta Z \rho_{l} \varepsilon_{l}
$$

or

$$
\frac{\Delta P_{f}}{\rho_{l} g \Delta Z}=\frac{\Delta P_{T}}{\rho_{l} g \Delta Z}-\varepsilon_{l}
$$

Hence,

$$
\Delta P=\frac{\Delta P_{T}}{\rho_{l} g \Delta Z}-\varepsilon_{l}
$$

In the present study frictional pressure $\operatorname{drop}(\Delta P)$ was calculated from Eq. (8).

\subsection{Effective Shear Rate}

For non-Newtonian liquids the viscosity is a function of shear rate and it is generally expressed as effective viscosity, $\mu_{\text {eff. }}$ The effective viscosity is defined as:

$$
\mu_{\text {eff }}=K \mathcal{E}_{\text {eff }}^{p-1}
$$

Schumpe and Deckwer [21] suggested the following expression for effective shear rare, $\psi_{e f f}$ for bubble column,

$$
\mathcal{\psi}_{\text {eff }}=2800 u_{g}
$$

\subsection{Effect of Taper Angle}


Fig. 3 shows the effect of taper angle on the frictional pressure drop, respectively. It is clear from the figures that as the taper angle decrease the frictional pressure drop increases. At lower taper angle back mixing is better and at higher taper angle the liquid near the wall in the top portion of the column remains unaffected, i.e. stagnant and hence, pressure drop decreases. With increasing the taper angle the cross sectional area, particularly in the upper zone, increases, which minimizes the transition of flow pattern and also reduces the coalescence. In the case of small taper angled bubble column the coalescence of bubbles is higher, large-sized bubbles having higher rise velocity and followed by small-sized bubbles. Few of these small-sized bubbles are recirculated and responsible for higher frictional pressure drop. Whereas for higher taper angled bubble column the rate of recirculation is low due to higher cross-sectional area in the upper zone.

\subsection{Correlation for Frictional Pressure Drop}

Empirical correlation for frictional pressure drop using SCMC solution is available in literature. Jawad [22] proposed the following empirical correlation in heterogeneous churn turbulent flow regimes.

$$
\Delta P=16108 n^{0.16} \mathrm{Re}_{g}^{-0.0398 n} \mathrm{Fr}_{g}^{0.037 n}
$$

Fig. 4 shows the comparison of total pressure drop data with Eq. (11).

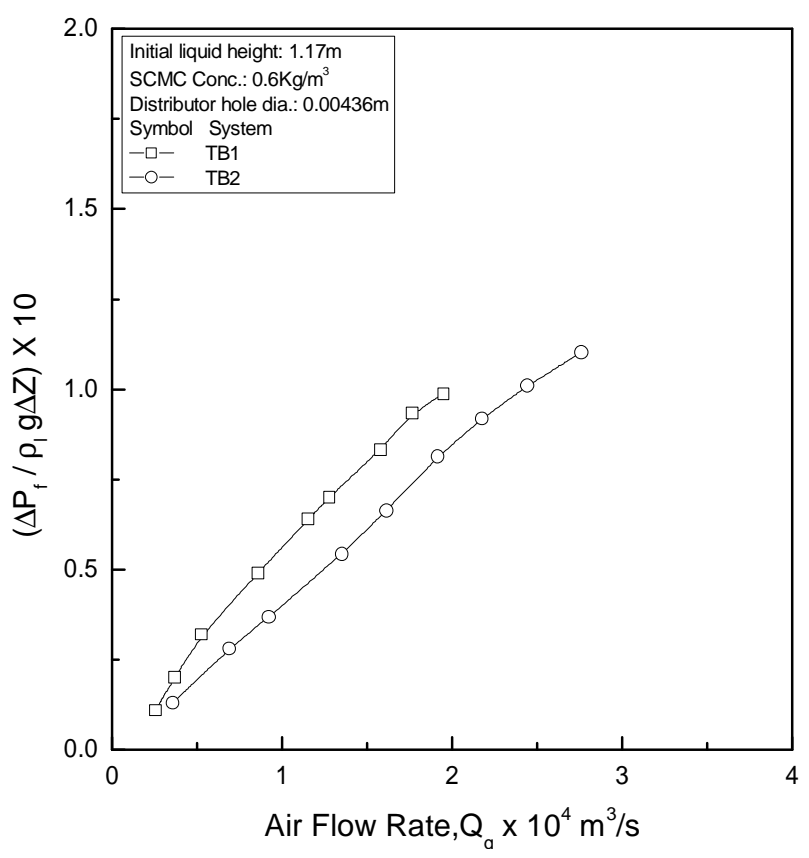

Fig. 3. Effect of the taper angle on frictional pressure drop
The experimental pressure drop is compared with the above equation and Table 2 shows the relative error (RE) and absolute error (AE). The relative error and absolute error are defined as:

$$
\begin{gathered}
R E=\frac{1}{N} \sum_{1}^{N} \mid\left(\frac{\Delta P_{\operatorname{expt}}-\Delta P_{c a l}}{\Delta P_{\text {exp } t}}\right) \times 100 \\
A E=\frac{1}{N} \sum_{1}^{N}\left|\left(\Delta P_{\exp t}-\Delta P_{c a l}\right)\right|
\end{gathered}
$$

From Table 3 Jawad [22] correlation does not correlate with the experimental data, hence, in the present case a correlation has been developed by dimensional analysis to predict the frictional pressure drop as a function of the physical properties, geometric and dynamic variables of the system. The parameters that affect the frictional pressure drop for tapered bubble columns using non-Newtonian liquids are:

(1) Physical properties of the gas and the liquid, namely, density $\rho_{g}$ and $\rho_{l}$; viscosity $\mu_{g}$ and $\mu_{\text {eff }}$; surface tension $\sigma_{l}$.

(2) Gas flow rate of the gas $Q_{g}$.

(3) Diameter of the column and distributor orifice diameter, namely, $D_{c}$ and $D_{n}$.

(4) Height of initial liquid in column, $H_{0}$.

(5) Taper angle (dimensionless), $\theta$.

(6) Other parameter like acceleration due to gravity, g.

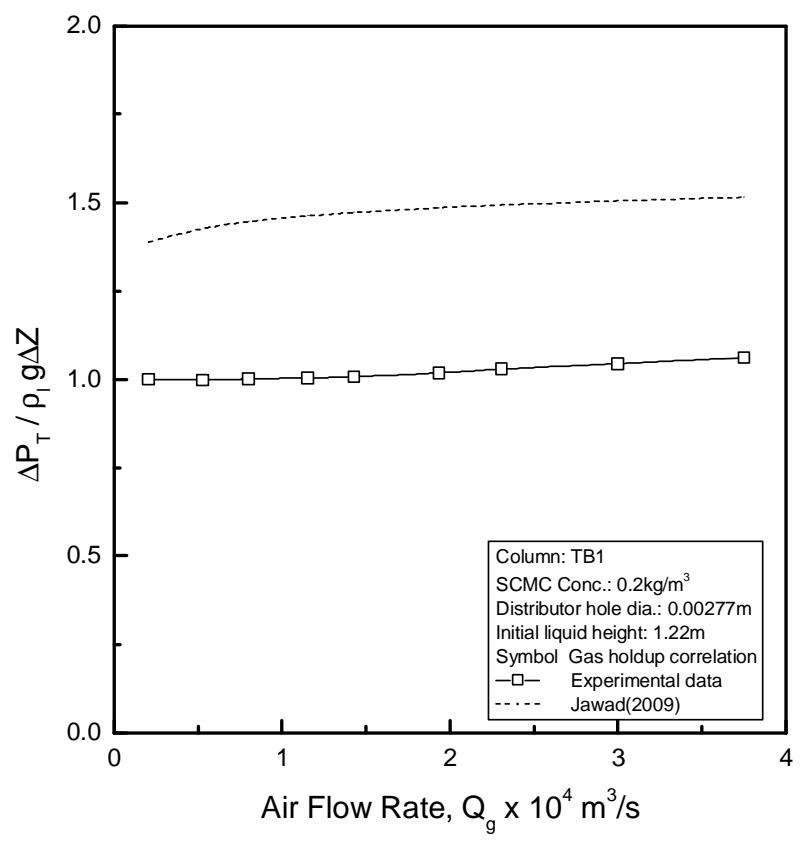

Fig. 4. Comparison of frictional pressure drop data with Jawad [22] correlation 


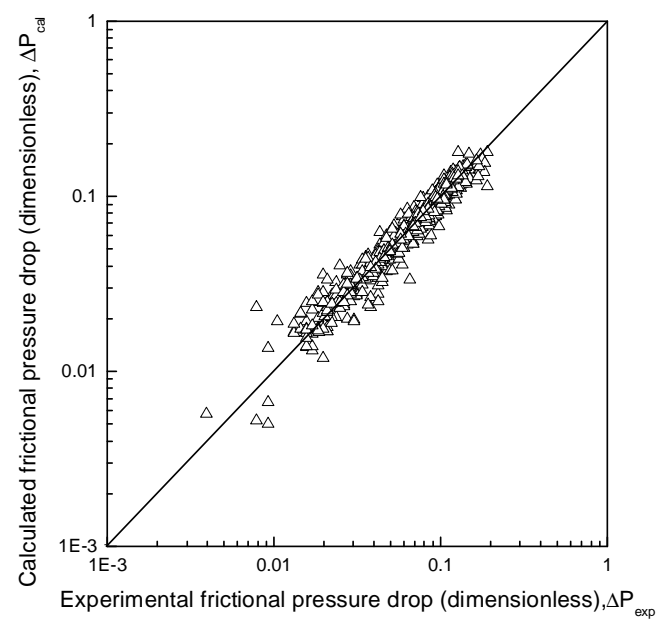

Fig. 5. Correlation plot of frictional pressure drop

The pressure drop may be written as a function of all these variables as:

$$
\frac{\Delta P_{f}}{\rho_{l} g \Delta Z}=F\left(Q_{g}, \mu_{g}, \rho_{g}, \rho_{l}, \mu_{e f f}, \sigma_{l}, H_{0}, D_{c}, D_{n}, \theta, g\right)
$$

The diameter of the column is calculated by calculating the equivalent diameter of the base and at the gas-liquid interface, then the log mean diameter for the column, $D_{c}$ is calculated. Hence, for each gas flow rate the column diameter $D_{c}$ varies according to the height of the gas-liquid interface. Applying the Buckingham's $\pi$ theorem of dimensional analysis and also combining some of these group yields the following functional relationship,

$$
\frac{\Delta P_{f}}{\rho_{l} g \Delta Z}=F\left(\operatorname{Re}_{g}, N_{p l}, \frac{H_{0}}{D_{C}}, \frac{D_{n}}{D_{c}}, \theta\right)
$$

On the basis of Eq. (12) the multiple linear regression analysis of the experimental data yielded the following correlation,

\section{Nomenclature}

$D_{c} \quad$ diameter of column (log mean), m

$D_{n} \quad$ distributor orifice diameter, $\mathrm{m}$

$g \quad$ acceleration due to gravity, $\mathrm{m} / \mathrm{s}^{2}$

$\Delta P_{f} \quad$ frictional pressure drop, $\mathrm{N} / \mathrm{m}^{2}$

$\Delta p_{h} \quad$ the column hydrostatic head, $\mathrm{N} / \mathrm{m}^{2}$

$\Delta p_{T} \quad$ total pressure drop, $\mathrm{N} / \mathrm{m}^{2}$

$\Delta p_{a} \quad$ pressure drop due to accelerative effect, $\mathrm{N} / \mathrm{m}^{2}$

$\Delta P \quad$ pressure drop,

$\Delta P=\frac{\Delta P_{T}}{\rho_{l} g \Delta Z}-\varepsilon_{l}$ (dimensionless)

$\Delta P \quad$ pressure drop in Eq. (11), $\mathrm{Pa}$

$H_{0} \quad$ initial liquid height in column, $\mathrm{m}$

$K \quad$ consistency index, $\mathrm{Ns} / \mathrm{m}^{2}$

$n \quad$ flow behaviour index

$Q_{g} \quad$ gas flow rate, $\mathrm{m}^{3} / \mathrm{s}$

$N_{p l} \quad$ Liquid property group, $N_{p l}=\frac{\mu_{e f f}^{4} g}{\rho_{l} \sigma_{l}^{3}}$ (dimensionless)

$R e_{g} \quad$ Reynolds number of gas, dimensionless

$$
\begin{gathered}
\frac{\Delta P_{f}}{\rho_{l} g \Delta Z}=8.071 X 10^{-4} \mathrm{Re}_{g}^{0.890 \pm 0.018} N_{p l}^{0.009 \pm 0.003} \times \\
\times\left(\frac{H_{0}}{D_{C}}\right)^{-0.350 \pm 0.040}\left(\frac{D_{n}}{D_{C}}\right)^{0.209 \pm 0.067} \theta^{-0.381 \pm 0.030}
\end{gathered}
$$

where the liquid property group, $N_{p l}=\frac{\mu_{e f f}^{4} g}{\rho_{l} \sigma_{l}^{3}}$, signifies some complex balance between viscous, surface tension and gravitational force. The values predicted by the Eq. (16) have been plotted against the experimental values as shown in Fig. 5.

The variance of the estimated and correlation coefficient of the above equation are 0.02472 and 0.9685 respectively for a $t$ value of 1.98 for 641 degrees of freedom at 0.05 probability levels and $95 \%$ confidence range [23].

Table 3

\section{Comparison of total pressure drop data with other correlation}

\begin{tabular}{|c|c|c|}
\hline Authors & RE, \% & $\mathrm{AE}$ \\
\hline Jawad [22] & 47.389 & 0.483 \\
\hline Eq. (16) & 0.780 & 0.008 \\
\hline
\end{tabular}

\section{Conclusions}

Experiments have been carried out to measure the frictional pressure drop for two different taper bubble columns using non-Newtonian pseudoplastic liquids. The frictional pressure drop increases with decrease of the taper angle. Empirical correlations have been developed to calculate frictional pressure drop as a function of various measurable parameters.

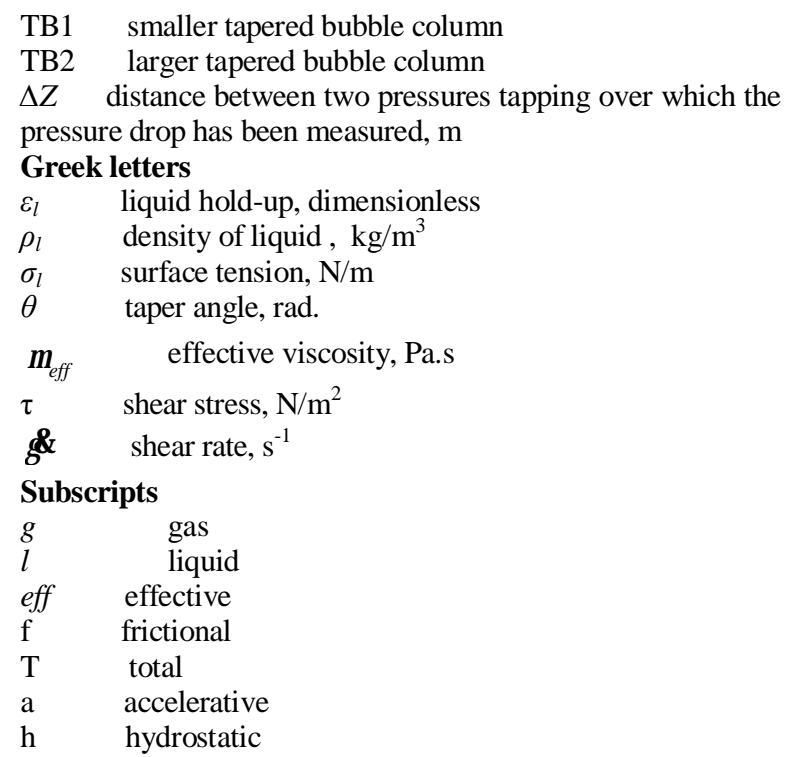




\section{References}

[1] Kulkarni A., Joshi J.: Ind. Eng. Chem. Res., 2005, 44, 5873. https://doi.org/10.1021/ie049131p

[2] Jana S., Biswas A., Das S.: Can. J. Chem. Eng., 2014, 92, 578. https://doi.org/10.1002/cjce.21838

[3] Chhabra R.: Bubbles, Drops \& Particles in non-Newtonian Fluids, $2^{\text {nd }}$ edn. CPC Press, Boca Raton 2006. https://doi.org/10.1201/9781420015386

[4] Pradhan A., Parichha R., De P.: Can. J. Chem. Eng., 1993, 71, 468. https://doi.org/10.1002/cjce.5450710319

[5] Mandal A., Kundu G., Mukherjee D.: Chem. Eng. and Proc., 2003, 42, 777. https://doi.org/10.1016/S0255-2701(02)00134-4

[6] Mandal A., Kundu G., Mukherjee D.: Chem. Eng. Sci., 2004, 59, 3807. https://doi.org/10.1016/j.ces.2004.03.037

[7] Frank X., Li H., Funfschilling D. et al.: Can. J. Chem. Eng., 2003, 81, 483. https://doi.org/10.1002/cjce.5450810321

[8] Zhan G., Zhao Y., Zhan B.: J. Chem. Res. Chinese Univ.., 2004, 20, 478 .

[9] Chandarkar S., Das S., Biswas M.: Int. Conf. Adv. Mechanical and Building Science in the $3^{\text {rd }}$ Millennium, 14-16 Dec. VIT University,TN 2009.

[10] Gomez-Diaz D., Navaza J., Quintans-Riveiro L.: Chem. Eng. J., 2009, 146, 16. https://doi.org/10.1016/j.cej.2008.05.022

[11] Anastasiou A., Passos A., Mouza A.: Chem. Eng. Sci., 2013, 98, 331. https://doi.org/10.1016/j.ces.2013.05.006

[12] Amirnia S., de Bruyn J., Bergougnou M., Margaritis A.: Chem. Eng. Sci., 2013, 94, 60. https://doi.org/10.1016/j.ces.2013.02.032

[13] Passos A., Voulgaropoulos V., Paras S., Mouza A.: Chem. Eng. Res. Des., 2015, 95, 93. https://doi.org/10.1016/j.cherd.2015.01.008

[14] Fernandez Y., Cartmell E., Soares A. et al.: Chem. Eng. J., 2015, 273, 656. https://doi.org/10.1016/j.cej.2015.03.051

[15] Sayeed-Bin-Asad S., Lundstrom T.: J. Multidis. Eng. Sci. Technol., 2015, 2, 2225.
[16] Jana S., Biswas A., Das S.: ChemXpress, 2014, 6.116.

[17] Hughmark G., Pressburg B.: AIChE J., 1961, 7, 677. https://doi.org/10.1002/aic.690070429

[18] Friedel L.: Int. Chem. Eng., 1980, 20, 352.

[19] Ros N.: J. Pet. Technol., 1961, 13, 1037. https://doi.org/10.2118/18-PA

[20] Hagedron A., Brown K.: J. Pet. Technol., 1965, 17, 475. https://doi.org/10.2118/940-PA

[21] Schumpe A., Deckwer W.: Ind. Eng. Chem. Process. Des. Dev., 1982, 21, 706. https://doi.org/10.1021/i200019a028

[22] Jawad Ali H.: Eng. Tech. J., 2009, 27, 1336.

[23] Volk V.: Applied Statistics of Engineers. McGraw-Hill Book Company, New York 1958.

Received: August 01, 2016 / Revised: October 26, 2016 / Accepted: J anuary 18, 2017

\section{КОНІЧНА БАРБОТАЖНА КОЛОНА З ВИКОРИСТАННЯМ ПСЕВДОПЛАСТИЧНИХ НЕНЬЮТОНІВСЬКИХ РІДИН - ЕМПІРИЧНА КОРЕЛЯЩІЯ ДЛЯ ВТРАТИ ТИСКУ}

Анотація. Проведені експериментальні дослідження 3 втрат тиску на тертя в двох конусоподібних барботажних колонах з використанням неньютонівських псевдопластичних рідин. Визначено вплив кута конусності на втрати тиску на тертя. Розроблено емпіричну кореляцію для передбачення втрат тиску в залежності від різних параметрів системи. Встановлено, щуо кореляція є в межах статистично прийнятної похибки.

Ключові слова: барботажна колона, неньютонівські рідини, втрати тиску. 